\title{
Biodegradation of monensin by rumen microorganisms in a Rusitec
}

\author{
F Mary-Vaufrey ${ }^{1}$, G Dauphin ${ }^{1}$, JP Jouany ${ }^{2}$ \\ 'URA 485 CNRS, Laboratoire de Chimie Organique Biologie, \\ Université Blaise Pascal, 63177 Aubière, Cedex; \\ ${ }^{2}$ INRA, Centre de Clermont-Ferrand/Theix, Station de Recherches sur la Nutrition \\ des Herbivores, Unité de la Digestion Microbienne, 63122 Ceyrat, France
}

Some carboxylic polyether antibiotics such as monensin are used to improve feed efficiency in ruminants. It is generally assumed that this antibiotic acts primarily on rumen microbes, but little is known about the modifications of its chemical structure in the rumen. We present here an NMR study of the transformation of monensin after $48 \mathrm{~h}$ fermentation in a Rusitec.

Monensin was added to the Rusitec either by continuous infusion in artificial saliva, or by once daily distribution in feed. During the first week, when microbes were allowed to adapt to Rusitec conditions, no monensin was added. During the second, third and fourth weeks, 2 fermenters received 5, 20 and $50 \mathrm{mg}$, and 2 others 10,30 and $100 \mathrm{mg}$ respectively. Liquid effluents were centrifuged for $10 \mathrm{~min}$ at $9800 \mathrm{~g}$.

The bacterial pellets and feed residues were extracted with ethanol and the supernatants with ethyl acetate. In a previous experiment we verified that this extraction method (Delort et al, 1988) gave quantitative results. After evaporation of the solvents, the extracts were purified and analysed by column chromatography with a $\mathrm{CHCl}_{3} / \mathrm{MeOH}$ gradient $\left(1.5\right.$ to $10 \% \mathrm{MeOH}$ in $\mathrm{CHCl}_{3}$ ). The fractions were analysed by NMR spectroscopy in $\mathrm{CDCl}_{3}$. ( ${ }^{1} \mathrm{H}$ spectra were recorded on a $\mathrm{MSL} 300 \mathrm{MHz}$ Bruker spectrometer).

The TLC analyses made on all concentrations and the NMR analyses made on samples during the last week only, clearly showed that no monensin was present in the supernatants or in the feed. However, $10 \%$ of monensin was detected in the bacterial pellets from the fermenters fed 50 and $100 \mathrm{mg}$ doses (fig 1). Consequently, it can be assumed that $90 \%$ of monensin was bioconverted by rumen microorganisms. In addition, the signal at $1.3 \mathrm{ppm}$ in the ${ }^{1} \mathrm{H}$ spectra of the supernatants and bacterial fractions suggests a possible degradation of monensin into fatty acids. This hypothesis should be confirmed by further studies using radiolabelled monensin.

Delort AM, Jeminet G, Sancelme $M$, Dauphin G (1988) J Antibiot 41, (7), 916-924

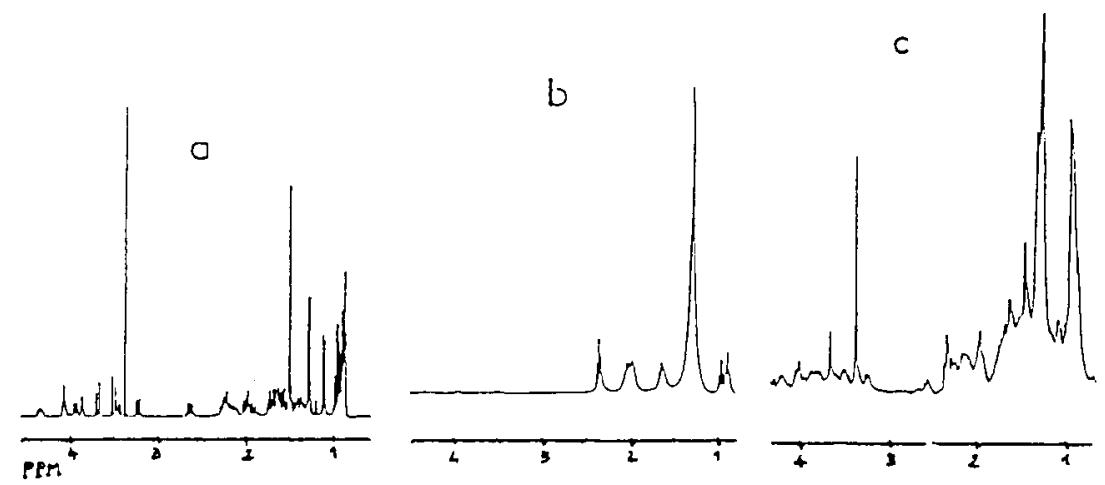

Fig 1. ${ }^{1} \mathrm{H}$ NMR spectra in $\mathrm{CDCl}_{3}$ of (a) pure monensin acid; (b) fraction of supernatant and (c) bacterial pellet. 